\title{
UPAYA PENINGKATAN WAWASAN NUSANTARA DALAM MENINGKATKAN SEMANGAT NASIONALISME BAGI WARGA NEGARA INDONESIA
}

\author{
Triana Devi Fatimah \\ IIK STRADA INDONESIA \\ 25triadevi062003@gmail.com
}

\begin{abstract}
Abstrak
Upaya untuk menanamkan jiwa nasionalisme pada warga negara Indonesia adalah dengan membuat konsep wawasan nusantara harus diketahui dan diketahui oleh setiap orang warga negara Indonesia melalui pengenalan warga negara secara geografis dan kondisi demografi Indonesia. Dengan pengenalan ini, upaya warga kesadaran akan kondisi negara akan merubah sikap warga negara menjadi upaya sadar dalam mempertahankan wilayah kedaulatan negaranya, sehingga setiap generasi tidak akan rela NKRI jatuh dan dikuasai oleh negara tetangga kita. Pemahaman Warga nusantara sangat penting wawasannya dipahami oleh setiap warga negara khususnya penyelenggara negara di negeri ini, demikian halnya dengan kasus Sipadan dan Ligitan tidak terulang dalam sejarah negara Indonesia.
\end{abstract}

\section{Kata Kunci : Pemahaman, Nasionalisme, Wawasan Nusantara.}

\section{A. Latar Belakang}

Perjuangan pengembangan Wawasan Nusantara ini masih terus berjalan. Konsepsi atau wawasan nusantara ini antara lain telah dan akan selalu mendukung kesatuan dan persatuan bangsa Indonesia perlu dipertahankan diperjuangkan dengan gigih didalam negeri atau di dunia Internasional. Namun demikian perlu disadari kesatuan dan persatuan yang merupakan titik sentral wawasan nusantara itu bukan Merupakan satu-satunya isi dari wawasan nusantara.

Dalam rangka memahami konsep Wawasan Nusantara menjadi melembaga Pada semua komponen masyarakat Indonesia, adalah yang paling utama adalah Menciptakan rasa nasionalisme kepada bangsa kita sendiri yang kaya akan segala potensi yang ada dialam Indonesia dan juga berusaha untuk dapat mempertahankan kesatuan dan persatuan kita untuk mempertahankan integritas bangsa Indonesia. Sekalipun nasionalisme masyarakat Indonesia sekarang ini masih dipertanyakan dengan muncunya berbagai permasalahan yang mengancam integritas Negara Kesatuan Republik Indonesia seperti sikap pemerintah Indonesia terhadap tanggung Jawab untuk menjaga dan mengelola negara ini. Dimana pada saat ini pulau-pulau Yang ada mulai dikuasai oleh negara lain (dimana dengan jatuhnya pulau Ambalat Dan Cipadan masuk wilayah terotorial Negara Malaysia), dan ancaman gerakan Separatis Gam, OPM dan RMS serta kerusuhan antar etnis dsb. Semua ini merupakan refleksi bahwa semangat nasionalisme dan kesadaran akan pemahaman wawasan nusantara masih perlu dikaji kembali kepada pihak - pihak pemerintah dan lebih khusus kepada warga Negara Indonesia.

\section{B. Tinjauan Pustaka}

\section{Pengertian Wawasan Nusantara}

Wawasan Nusantara adalah cara pandang sebuah bangsa tentang dirinya ditengah-tengah lingkungan strategis yang bergerak serba cepat dan dinamik, agar bangsa tersebut tetap eksis dan 
survife. Pengertian lain dari wawasan nusantara secara termininologi wawasan nusantara diartikan sebagai cara pandang sebuah nation state tentang diri dan lingkungan strategiknya yang berubah serba dinamik dengan Mempertimbangkan aspek cultural, histories, geografis, ruang hidup, idealisme, falsafah Negara, konstitusi, aspirasi, identitas, integritas kelangsungan hidup dan perkembangan kehidupannya serta kemampuannya dan daya saingnya.

Menurut M.Panggabean (1979 : 349) wawasan nusantara adalah doktrin politik bangsa Indonesia untuk mempertahankan kelangsungan hidup Negara Republik Indonesia, yang didasarkan pada Pancasila dan UUD 1945 dengan memperhitungkan pengaruh geografi, ekonomi, demografi, teknologi dan kemungkinan strategik yang tersedia. Dengan perkataan lain, wawasan nusantara adalah geopolitik Indonesia. Dan nilai yang terkandung didalam wawasan nusantara telah diintegrasikan didalam lima aspek secara intern yaitu kesatuan wilayah, kesatuan bangsa, kesatuan ekonomi, kesatuan budaya, dan kesatuan pertahanan Sedangkan untuk ekstern nilai integrasi itu diusahakan dengan ikut mewujudkan ketertiban dunia yang berdasarkan kemerdekaan perdamaian abadi dan keadilan sosial.

Memperhatikan proses pertumbuhan itu, nyata benar bahwa wawasan nusantara tersebut masih terikat kepada konsepsi-konsepsi kekuatan. Oleh sebab itu, pemikiran-pmikiran yang kini sedang berkembang jelas mengarah kepada usaha untuk dapat menyusun dan merumuskan" Wawasan Nusantara" sebagai suatu "Wawasan Nasional", yang tidak hanya diperuntukkan bagi Hankamnas saja, melainkan yang dapat menyeluruh meliputi "segenap segi kehidupan nasional", hingga dapat mendasari konsepsi ketahanan nasional. Demikianlah tumbuh pemikiran-pemikiran dan pengkajian mengenai wawasan nusantara sebagai salah satu aspek daripada falsafah hidup nasional kita, yang berisi dorongan-dorongan dan rangsangan-rangsangan untuk mencapai tujuan serta aspirasi-aspirasi nasional kita.

Seperti keadaan sekarang menunjukkan, bahwa bergeraknya arah pemikiran-pemikiran untuk mencakup segenap aspek-aspek kehidupan nasional kita, guna dapat menemukan jawaban dan perumusannya, bagaimana kita menyusun suatu konsepsi strategis untuk menyelenggarakan dan menjamin tata-kelangsungan hidup nasional kita, seperti halnya telah berhasil kita rumuskan dalam konsepsi ketahanan nasional. Sesungguhnya, kelangsungan itu dituntut oleh hidup sendiri, karena tanpa kelangsungan, hidup itu akan mandek. Dan "mandek"nya hidup, berarti mati. Oleh sebab itu, disamping kita harus menyelenggarakan dan menjamin tata-pengamanan hidup nasional kita, maka yang terpokok justru kita harus pertama-tama menyelenggarakan dan menjamin tatakelangsungannya. Untuk maksud dan tujuan itulah perlunya kita mengkonsepsi Wawasan Nusantara, yang menyeluruh-bulat dan utuh lengkap meliputi segenap aspek perkehidupan nasional kita.

Wawasan nusantara adalah Geopolitik Indonesia, berwawasan dua arah yaitu keluar dan kedalam. Pancasila dan pembukaan UUD 1945 menetapkan nilai instrinstik yang mendasari wawasan nusantara yang nilai integrasi yang di tujukan pada kehidupan internal bangsa maupun kehidupan antar bangsa. Sebagai geopolitik Indonesia, wawasan nusantara memawas Negara Indonesia dari sudut pandang, yaitu (1) Negara sebagai wilayah, (2) Negara dalam pengertian rakyat yang hidup dalam Wilayah itu, (3) Negara sebagai kehidupan masyarakat, (4) negara sebagai suatu Penyelenggaraan rumah tangga, dan (5) Negara sebagai penjamin kelangsungan hidup dirinya.

Untuk pencapaian tujuan ini, wawasan nusantara telah mengidentifikasikan lima aspek integrasi yang harus di pegang teguh dalam menyelenggarakan kehidupan negara, yaitu : pertama, Satu kesatuan wilayah dalam arti bahwa wadah bangsa yang sarwa nusantara dengan segala isi dan kekayaanya merupakan satu kesatuan tumpah darah. Kedua, satu kesatuan bangsa dalam arti bahwa bangsa Indonesia memiliki satu ideology yaitu pancasila yang melandasi, membimbing dan megarahkan bangsa dalam mencapai tujuannya, serta memiliki UUD dan politik pelaksanaanya. Memiliki rasa senasib dan sepenanggungan serta satu tekad untuk mencapai. Ketiga, Satu kesatuan sosial budaya dalam arti bahwa perwujudan budaya nasional atas dasar asas Bhineka Tunggal Ika 
merupakan modal dan landasan pengembangan budaya bangsa, selanjutnya budaya bangsa dapat di nikmati oleh bangsa Indonesia dengan pengertian bangsa bahwa budaya Indonesia hakekatnya adalah satu, sedangkan corak ragam budaya yang ada, menggambarkan kekayaan budaya bangsa; pula memiliki satu tertib sosial dan tertib hukum yang mengabdikan diri kepada kepentingan nasional. Keempat, Satu kesatuan ekonomi dalam arti bahwa perekonomian di susun sebagai usaha bersama berdasar asas kekeluargaan kekayaan seluruh wilayah nusantara merupakan modal serta milik seluruh bangsa yang pengembangan dan pembinaannya di selenggarakan secara seimbang dan serasi tanpa meninggalakan ciri khas yang di miliki oleh tiap daerah dalam pengembangan kehidupan ekonominya. Kelima, satu kesatuan Hankam dalam arti bahwa pembinaan hankam di laksankan berdasarkan daya rakyat semesta dengan angkatan bersenjata sebagi intinya dan bahwa ancaman terhadap suatu pulau atau satu daerah hakekatnya merupakan ancaman terhadap seluruh bangsa serta negara dan bahwa tiap-tiap warga negara mempunyai hak melakukan pembelaan terhadap negara.

\section{Pembahasan}

\section{Upaya yang dilakukan dalam rangkah memperkokoh kadar pemahaman Wawasan Nusantara.}

Upaya yang yang dapat dilakukan oleh pemerintah maupun masyarakat untuk memahami eksistensi negara Indonsia sebagai negara kepulauan dengan batas-batas wilayah sebagaimana yang terdapat dalam Deklarasi Djuanda yang telah menyatukan wilayah laut In dosnesia dengan tidak lagi memberi ruang pada kantong-kantong laut internasioanl yang berada diantara pulau-pulau Indonesia. Dengan mengenal wilayah laut setiap warga negara Indonesia akan tumbuh semangat nasionalisme untuk mencintai dan mempertahankan keutuhan wilayah negara Kesatuan Republik Indonesia. Keinginan tersebut dapat dilakukan lewat pendidikan Pancasila dan Pendidikan Kewarganegaraan yang diberikan disemua tingkatan pendidikan maupun pada pendidikan non formal dengan memperkenalkan eksistensi wawasan nusantara yang banyak memiliki potensi yang dapat menghidupi masyarakat Indonesia, dan juga memperkenalkan kepada semua warga negara tentang kerawanan-kerawanan wilayah Republik Indonesia dalam menghadapi negara-negara lain terutama negara yang ada dalam batas-batas dengan wilayah negara kita.

Pemahaman yang sangat penting bagi warga Negara Indonesia adalah memahami konsep negara kita sebagai negara kepulauan sebagaimana yang telah dapat diwujudkan dalam Deklarasi Djuanda pada tanggal 13 Desember 1957 wilayah kita yang tadinya hanya 3 mil menjadi 12 mil sebagaimana isi dari Deklarasi tersebut telah dapat menyatukan seluruh wilayah Negara kesatuan Republik Indonesia, sehingga tidak ada lagi laut internasional diantara pulaupulau yang ada di Indonesia.

Kekalahan pemerintah RI dalam mempertahankan kedaulatan negara terhadap pulaupulau terluar karena pemerintah tidak melakukan diplomasi di PBB tentang batas wilayah RI sebagaimana yang telah dilakukan oleh negara-negara Malaysia dalam merebut pulau Ambalat, Sipadan dan Ligitan, mereka mampu memperjuangkan batas-batas wilayah diforum internasional dan mendapat pengakuan dan kepastian hukum. Oleh karenanya pemerintah harus memiliki kemampuan secara politik maupun dasar hukum Internasional menempatkan batasbatas wilayah RI diforum internasional (PBB). Sehingga kekuatan hukum terhadap batas-batas wilayah perairan Indonesia tidak dicaplok oleh negara-negara lain terutama negara-negara tetangga yang berbatasan dengan pulau-pulau di Indonesia . 
Partisipasi masyarakat sangat dibutuhkan dalam menjaga keutuhan wilayah Negara kesatuan RI dengan cara-cara melakukan aktivitas yang tidak mengancam integritas Negara kesatuan RI. Misalnya upaya menyeledupkan hasil-hasil potensi alam kita ke negara lain, seperti illegal loging maupun illegal fishing. Keikut sertaan masyarakat dalam menjaga aktifitas yang dapat merugikan kepentingan umum telah ikut bersama-sama berpartisipasi dalam mewujudkan integritas Negara Kesatuan Republik Indonesia.

Pelembagaan pengenalan terhadap wawasan nusantara dalam kehidupan bermasyarakat, berbangsa dan bernegara dapat dilakukan melalui pendidikan yang terbagi atas pendidikan formal maupun pedidikan non formal.

\section{a. Pendidikan Formal.}

Dalam mewujudkan pelembagaan penegenalan eksistensi wilayah laut (wawasan Nusantara dilakukan melalui kurikulum yang sekarang diberikan disemua tingkatan pendidikan formal Pendidikan yang diberikan ada pada pelajaran pendidikan kewarganegaraan yang memperkenalkan terhadap semangat nasionalisme betapa beratnya para pendiri Negara mewujudkan Negara kepulauan yang sangat sulit diperjuangkan sehingga negara kita disebut sebagai negara kepulauan karena batasbatas wilayah laut Indonesia telah menjadi satu kesatuan wilayah hal ini di nyatakan dalam Deklarasi Djuanda pada tanggal 13 Desember 1957 dimana luas wilayah laut kita telah menjadi 12 mil dari semula hanya 3 mil . sosialisasi melalui pendidikan formal ini menciptakan rasa kesadaran terhadap nasionalisme yang dapat diwujudkan dengan keikut sertaan menjaga eksistensi negara kita dari ancaman negara-negara lain.

\section{b. Pendidikan Non formal.}

Sosilisasi pemahaman wawasan nusantara dapat juga dilakukan lewat pendidikan non formal, dimana masyarakat dilibatkan dalam diklat tentang wawasan kebangsaan dengan tujuan agar supaya semua komponen warga Negara Indonesia mengenal batas-batas wilayah laut atau perairan dan darat, udara Indonesia. Semua ini dilakukan supaya perjuangan para pendiri negara yang telah berusaha mencapai batas-batas territorial wilayah Indonesia dapat dipertahankan perjuangan oleh generasi sekarang ini. karena ditangan generasi sekarang inilah negara Indonsia akan tetap eksis sepanjang masa. Kesadaran pemahaman wawasan nusantara dapat menghilangkan rasa kedaeraan yang sering muncul dalam diri kita, oleh karenanya setelah kita mengenal bahwa seluruh wilayah yang ada di Indonesia ini adalah satu kesatuan akan dapat memperkokoh semangat nasionalime kita terhadap Negara kesatuan Republik Indonesia.

\section{c. Lewat Media informasi.}

Untuk menjangkau sosialisasi pemahaman wawasan nusantara ke seluruh lapisan masyarakat Indonesia yang tersebar dalam 32 Propinsi dapat dilakukan melalui media masa atau elektonik, oleh karenanya peranan TV negeri maupun swasta sangat mendukung mensosialisasikan konsep wawasan nusantara pada masyarakat. Dengan politik media dari berbagai negara lain diera globalisasi ini pun menjadi tantangan kita bersama agar supaya masyarakat kita tidak terpengaruh oleh media yang dapat menurunkan semangat nasionalisme. Melalui media kita dapat memperkenalkan langsung tentang eksistensi negara kita. Namun upaya ini belum merata didaerah-daerah yang sangat terisolir dengan sarana komunikasi yang terbatas. Untuk itu pemerintah harus berupaya memfasilitasi sarana tersebut sehingga mempermudah jangkauan sosialisasi kita dalam mensosialisaikan wawasan nusantara demi menciptakan masyarakat yang mampu mempertahankan integritas Negara 
kesatuan Rpublik Indonesia.

Dengan melalui sosialisasi wawasan nusantara ini dapat dipahami oleh warga masyarakat. Dengan demikian dapat memperkuat semangat nasionalisme untuk saling menyadari bahwa kita sebetulnya berasal dari sejarah yang sama, nenek moyang sama yang telah menjadi satu komunitas negara yang akan mewujudkan harapan menuju kepada cita-cita menggapai masyarakat yang adil dan makmur sebagaimana yang terdapat dalam rumusan pembukaan Undang-Undang Dasar 1945.

\section{Kesimpulan}

Berdasarkan permasalahan dalam kajian ini tentang upaya peningkatan pemahaman wawasan nusantara sebagai sarana dalam meningkatkan semangat nasionalisme bagi warga negara Indonesia dapat ditarik beberapa hal yang dianggap sangat penting diperhatikan sbb : Pertama, Kondisi pemahaman wawasan nusantara saat ini dapat dilihat dengan kegagalan pemerintah pusat dalam upaya menciptakan stabilitas baik didalam negeri maupun luar negeri. Realitas yang nampak adalah dimana batas wilayah Negara kesatuan yang telah dicaplok oleh negara-negara lain seperti Malaysia menunjukan kepada kita ketidak mampuan pemerintah kita dalam menjaga keutuhan wilayah Negara kesatuan RI sebagai Negara kepulauan. Gerakan separatis yang mewarnai problem pemerintahan kita menujukan pula ada sesuatu yang salah dalam pelaksanaan kebijakan pemerintahan pusat pada daerah. Dengan

demikian kebijakan otonomi daerah yang tadinya sebagai solusi alternatif pemecahan masalah, justru menimbulkan konflik didaerah. Kedua, Faktor-faktor yang mempengaruhi memudarnya pemahaman wawasan nusantara dan rasa nasionalisme adalah disebabkan oleh karena faktor internal dan eksternal, dimana nasionalisme menurun sebagaimana yang dijelaskan diatas ada beberapa faktor penghambat mewujudkan nasinalisme dintaranya karena penyelenggara negara dan masyarakat tidak memahami konsep kedaulatan negara kita sebagai negara kepulauan, budaya egosentrisme, etnonasionalisme, dan pemahaman konsep inplementasi otonomi daerah yang sempit yang memunculkan sikap etnosentrisme pada masyarakat lokal, semua ini menjadi penghambat membangun semangat nasionalisme. Ketiga, Kondisi pemahaman wawasan nusantara yang diharapkan kepada warga Negara Indonesia lebih khusus kepada pihak pemerintah agar supaya dapat mencintai dan mempertahankan keutuhan sebagai Negara kepulauan adalah khusus dibidang Persatuan Indonesia. Usaha memelihara persatuan berdasarkan wawasan nusantara adalah diharapkan kepada bangsa ini bisa menjadikan seluruh warga Negara Indonesia memiliki rasa satu bahasa, senasib sepenanggungan, setanah air, serta mempunyai satu tekad dalam mencapai cita-cita bangsa. Hal ini perlu disadari oleh adanya satu kenyataan bahwa Indonesia terdiri dari bermacam-macam agama, suku, adat dan kebiasannya, serta berbeda-beda faham dan aspirasinya. Keempat, Pemasyarakatan wawasan nusantara dalam kehidupan bermasyarakat, berbangsa dan bernegara dapat dilakukan lewat pendidikan formal dan non formal dengan memberikan pengenalan terhadap eksistensi negara kita sebagai Negara kepulauan sebagaimana yang terdapat dalam Deklarasi Djuanda yang ditandatangani pada tanggal 13 Desember 1957 yang memberikan penjelasan tentang batas wilyah perairan Indonesia yang semula hanya 3 mil bertambah menjadi 12 mil yang telah menghubungkan semua perairan antar pulau diIndonesia. Dengan demikian dari hasil Deklarasi itu telah menghilangkan wilayah laut internasional atau kantong-kantong wilayah internasional yang dapat mengancam integritas Negara kesatuan Republik Indonesia. 


\section{DAFTAR PUSTAKA}

M. Budiyarto Tahun 1980"Wawasan Nusantara dalam peraturan PerundangUndangan Negara Republik Indonesia” Penerbit Ghalia Indonesia.

Diamond.Larri Tahun 1998"Nasionalisme konflik etnik dan Demokrasi" Penerbit ITB

Siyoto, S., \& Sodik, M. A. (2015). Dasar metodologi penelitian. Literasi Media Publishing.

Sodik, M. A., Suprapto, S. I., \& Pangesti, D. (2013). Faktor-Faktor Yang Berhubungan Dengan Pelaksanaan Pelayanan Prima Pegawai Di Rsui Orpeha Tulungagung. STRADA Jurnal Ilmiah Kesehatan, 2(1), 24-32.

Sodik, M. A. (2018). Merokok \& Bahayanya.

Sodik, M. A., \& Nzilibili, S. M. M. (2017). The Role Of Health Promotion And Family Support With Attitude Of Couples Childbearing Age In Following Family Planning Program In Health. Journal of Global Research in Public Health, 2(2), 82-89.

Attoriq, S., \& Sodik, M. A. (2018). Pencegahan Dan Pengendalian Infeksi Terkait Pelayanan Kesehatan Di Lahan Praktik.

Sodik, M. A. (2018, September). Analysis of Improved Attitude of Youth in HIV/AIDS Prevention through the Provision of Health Education with Peer Education. In The 2nd Joint International Conferences (Vol. 2, No. 2, pp. 495-502).

Sodik, M. A., \& Setyani, A. T. (2018). Effect of Smoking For Teens Against Behavior and Social Interaction.

Fatimah, T. D. (2021). PERKEMBANGAN DAN PERMASALAHAN HAK KESETARAAN DALAM PELAYANAN KESEHATAN DI MASYARAKAT.

Fatimah, T. D. (2021). KEDUDUKAN BHINEKA TUNGGAL IKA UNTUK MEMPERKUKUH NEGARA KESATUAN REPUBLIK INDONESIA DI MASA PANDEMI.

Fatimah, T. D. (2021). Membangun Kualitas Sistem Politik Demokrasi Indonesia Melalui Pemilu Dalam Perspektif Integrasi Bangsa Dengan Berorientasikan Ideologi Pancasila. 